\title{
Analysis of the black-chinned tilapia Sarotherodon melanotheron heudelotii reproducing under a wide range of salinities: from RNA-seq to candidate genes
}

\author{
J.-C. Avarre ${ }^{1, *}$, R. Dugué ${ }^{1}$, P. Alonso ${ }^{1}$, A. Diombokho ${ }^{1}$, C. Joffrois ${ }^{1}$, N. Faivre ${ }^{1}$, C. Cochet $^{1}$, \\ J.-D. Durand ${ }^{2}$
}

\begin{abstract}
${ }^{1}$ Institut des Sciences de l'Evolution de Montpellier, UMR 226 IRD-CNRS-UM2, Montpellier Cedex 05, France
2 Ecologie des Systèmes Marins Côtiers, UMR 5119 IRD-UM2-CNRS-IFREMER, Montpellier cedex 05, France

*: Corresponding author : Jean-Christophe Avarre, fax. +33467143622 ; email address : jean-christophe.avarre@ird.fr
\end{abstract}

\begin{abstract}
:
The black-chinned tilapia Sarotherodon melanotheron heudelotii is an ecologically appealing model as it shows exceptional adaptive capacities, especially with regard to salinity. In spite of this, this species is devoid of genomic resources, which impedes the understanding of such remarkable features. De novo assembly of transcript sequences produced by next-generation sequencing technologies offers a rapid approach to obtain expressed gene sequences for non-model organisms. It also facilitates the development of quantitative real-time PCR (qPCR) assays for analysing gene expression under different environmental conditions. Nevertheless, obtaining accurate and reliable qPCR results from such data requires a number of validations prior to interpretation. The transcriptome of S. melanotheron was sequenced to discover transcripts potentially involved in the plasticity of male reproduction in response to salinity variations. A set of 54 candidate and reference genes was selected through a digital gene expression (DGE) approach, and a de novo qPCR assay using these genes was validated for further detailed expression analyses. A user-friendly web interface was created for easy handling of the sequence data. This sequence collection represents a major transcriptomic resource for $S$. melanotheron and will provide a useful tool for functional genomics and genetics studies.
\end{abstract}

Keywords : gene expression ; non-model organism ; reference gene ; salinity ; spermatogenesis ; tilapia 


\section{Introduction}

Inland water ecosystems are subjected to natural, seasonal and between-year variations in climate. Depending on their nature, duration and magnitude, these variations have contributed to the evolution of physiological adaptations in fish species. These adaptations consist in modifications of life history traits such as growth, age at sexual maturity (Duponchelle\& Panfili 1998; Stearns\& Crandall 1984; Stewart 1988), fecundity (Duponchelle et al. 2000; Legendre\& Ecoutin 1989) or trophic demand (Ogari\& Dadzie 1988). In this context, a better delimitation of the adaptive capacities of species, and a deeper understanding of their inner mechanisms, are tremendously needed to determine the threats upon these species. This issue is particularly overwhelming in the field of reproductive biology, which has a more straigntforward impact on fitness than any other biological function.

Species that already perform well or are tolerant to a broad range of environmental conditions are thus excellent templates for investigating the responses to such fluctuations. In this regard, the black-chinned tilapia Sarotherodon melanotheron heudelotii Rüppell 1852 (Teleostei, Cichlidae) is supposedly one of the record holders, since it has been reported to reproduce at salinities ranging from 0 to 120 psu (Panfili et al. 2004; Panfili et al. 2006). This tilapia is a mouthbrooding fish in which the males pick up the fertilized eggs and incubate them until they are released as free-swimming fry. In addition, the black-chinned tilapia $S$. melanotheron is an excellent model for studying the plasticity of reproductive traits since: i) it shows a remarkable adaptation to salinity and is, to our knowledge, the most plastic fish in this respect; ii) natural populations occur in many different habitats from fresh- to hypersaline waters ; iii) in culture conditions, it is capable of spawning spontaneously and has brief and frequent reproduction cycles all year round; iv) it has a relatively small size and it is thus easy to maintain adult fishes in different controlled conditions. 
Using suppressive subtractive hybridization from gills of $S$. melanotheron, Tine et al. demonstrated how salinities impacted the expression of a small number of genes involved in osmotic homeostasis and energy metabolism (Tine et al. 2008; Tine et al. 2012), thereby highlighting a plastic regulation of gene expression in the gills. If the plasticity of the reproductive traits of $S$. melanotheron induced by salinity are now acknowledged (Legendre et al. 2008; Panfili et al. 2006), the underlying biological processes are still poorly understood, mainly because of the lack of genomic resources available for this species. The present study aimed at filling this gap, by generating a large transcript sequence collection. In non-model organisms for which there is no or limited genomic resources, next-generation sequencing (NGS) represents a valuable tool for characterizing genes involved in particular biological functions or traits (Fraser et al. 2011; Wang et al. 2009). Once a reference transcriptome is available, tag-based sequencing, or digital gene expression (DGE), represents a sensitive and cost-effective alternative for gene expression profiling of specific phenotypes or adaptive traits (Hong et al. 2011; t Hoen et al. 2008). Then, real-time PCR (qPCR) remains the simplest and probably most accurate method to substantiate quantitative data derived from NGS. Yet, obtaining, analysing and interpreting qPCR data is not a trivial issue, and requires a thorough validation of every step of any de novo assay design (Bustin et al. 2010). Therefore, the present article describes not only the development of an important transcriptomic resource for $S$. melanotheron, but also the detailed validation of a set of candidate and reference genes that will enable in-depth expression studies on both wild and experimental fish populations, complying with the MIQE (Minimum Information for publication of Quantitative real-time PCR Experiments) guidelines (Bustin et al. 2009). 


\section{Material and methods}

Fish sampling

Natural populations of $S$. melanotheron heudelotii were sampled in Senegal during the dry season (May 2010) at 3 locations along the salinity gradient of the Sine Saloum estuary, namely Missirah (40 psu), Foundiougne (53 psu) and Kaolack (95 psu). Adult fish were caught using a cast net and then anesthetized in icy water. Size (fork length) and weight were measured and the sex determined for each fish. Animals were dissected and a portion of both liver and gonad was immediately immersed in a tube containing 10-20 volumes of RNAlater (Ambion) and placed on ice. Tubes were maintained at $4^{\circ} \mathrm{C}$ all along the field campaign (3 days), and stored at $-20^{\circ} \mathrm{C}$ upon arrival to the laboratory. The stage of sexual maturity was determined macroscopically according to Legendre and Ecoutin (Legendre\& Ecoutin 1989). A total of 10 males and 10 females were collected from each station.

\section{RNA extraction}

RNA was extracted with the Nucleospin-8 total RNA isolation kit (Macherey-Nagel). Fifteen to twenty mg of tissue preserved in RNA later (Ambion) were weighed and transferred into 2$\mathrm{ml}$ tubes containing a 5-mm steel bead (Qiagen) as well as $360 \mu 1$ lysis buffer supplemented with $1 \% \beta$-mercaptoethanol (Sigma-Aldrich). Tissues were homogenized with a tissue lyzer (Qiagen) for $2 \mathrm{~min}$ at $50 \mathrm{~Hz}$. Tubes were then centrifuged for $5 \mathrm{~min}$ at 20,000 $\mathrm{g}$ and the supernatants were transferred to new tubes and kept at $-20^{\circ} \mathrm{C}$ overnight. RNA was extracted the following day according to the manufacturer's instructions, using a Janus automated Workstation (Perkin Elmer), and eluted in $70 \mu \mathrm{l}$ RNase-free $\mathrm{H}_{2} \mathrm{O}$. In order to remove any trace of contaminating genomic DNA, RNA eluates were subjected to a second DNase treatment. Briefly, a mix of $0.2 \mu 1$ RNase-free DNase and $2 \mu 1$ of reaction buffer (Macherey- 
Nagel) was added to $20 \mu 1$ of each RNA eluate, and digestion was carried out for $15 \mathrm{~min}$ at $37^{\circ} \mathrm{C}$. RNA quantity was measured by UV spectrophotometry (Nanodrop 1000, Thermoscientific), and its integrity was verified by capillary electrophoresis (Agilent Bioanalyzer 2100). Only samples displaying an RNA integrity number (RIN) $\geq 8$ were used for subsequent analyses. Each RNA sample was diluted to a concentration of $50 \mathrm{ng} / \mu \mathrm{lin} \mathrm{H}_{2} \mathrm{O}$ and stored at $-80^{\circ} \mathrm{C}$.

\section{RNA-seq library}

\section{Construction and sequencing}

A large transcript library was generated from both liver and gonads of wild fish sampled in the Sine Saloum estuary. RNA from liver and gonads of 18 males and 16 females $(\sim 5-6$ fish per salinity location) were mixed in an equimolar way. Five $\mu \mathrm{g}$ of this RNA mixture were used as template for the construction of a cDNA library, using the Illumina mRNA-Seq Paired-End kit with several modifications. In brief, polyA-containing mRNA molecules were fragmented for 5 min to yield fragments of $\sim 250 \mathrm{bp}$. Second strand cDNA was synthesized and further subjected to end repair, A-tailing, and adapter ligation in accordance with the manufacturer supplied protocols. Purified cDNA templates were enriched by 15 cycles of PCR for $10 \mathrm{~s}$ at $98^{\circ} \mathrm{C}, 30 \mathrm{~s}$ at $65^{\circ} \mathrm{C}$, and $30 \mathrm{~s}$ at $72^{\circ} \mathrm{C}$ using PE1.0 and PE2.0 primers and with Fastart taq DNA polymerase (Roche). The samples were cleaned using QIAquick PCR purification columns and eluted in $30 \mu \mathrm{l}$ elution buffer. The purified cDNA library was quantified using Bioanalyzer DNA 100 Chips (Agilent Technology 2100 Bioanalyzer). Cluster generation was performed by applying $4 \mathrm{pM}$ of cDNA to an Illumina $1 \mathrm{G}$ flowcell. Hybridization of the sequencing primer, base incorporation, image analysis and base calling were carried out using the Illumina Pipeline. 
Contig assembly and functional annotation

Analysis and assembly of the RNA-seq library, which consisted in 50-bp paired-end sequences, were performed by Skuldtech Company (www.skuldtech.com). A first assembly was done using Velvet 1.0.09 $(k$-mer $=41)$. Sequences were then assembled into clusters using MIRA v3.1. Overlapping identity percentage and minimum overlapping length parameters were set to $90 \%$ and $60 \mathrm{bp}$, respectively, in order to obtain highly reliable consensus sequences. Sequences that could not be assembled at this stage were referred to as singletons and were not taken into consideration in the following steps. In contrast, the resulting contigs were translated into six reading frames and used as a query to search the non-redundant protein databases available at the National Center for Biotechnology

153 Information (NCBI) using the BlastX algorithm with an E-value $\leq 10^{-3}$ (version \# 2.2.15, GenBank release number \#166) (www.ncbi.nlm.nih.gov). Sequences with BlastX hits were assigned to the following five sequence categories: known, uncharacterized, predicted, unknown or unnamed, and hypothetical proteins. These terms correspond to the "definition" category of available protein sequences deposited on GenBank (http://www.ncbi.nlm.nih.gov/pubmed/). All unique sequences with BlastX hits (E-value $\leq$ $10^{-3}$ ) were functionally annotated using Blast2GO (http://www.blast2go.org/) by mapping against gene ontology $(\mathrm{GO})$ resources.

Construction and sequencing of digital gene expression (DGE) libraries

Two DGE libraries were constructed with testis RNA obtained from five males collected at Missirah (salinity $40 \mathrm{psu}$ ) and five males collected at Kaolak (salinity 95 psu). Sequence tag preparation was achieved with Illumina's Digital Gene Expression Tag Profiling Kit 
according to the manufacturer's protocol (version 2.1B). For each library, $5 \mu \mathrm{g}$ of an equimolar mix of the 5 total RNA samples were incubated with oligodT beads. Synthesis of first- and second-strand cDNA was performed using superscript II reverse transcription kit according to the manufacturer's instructions (Invitrogen). The cDNAs were cleaved using the NlaIII anchoring enzyme. Subsequently, digested cDNAs were ligated with the GEX adapter 1 containing a restriction site of MmEI. A second digestion with MmeI was then performed, which cuts $17 \mathrm{bp}$ downstream of the CATG site. At this point, the fragments detached from the beads. Then the GEX adapter 2 was ligated to the 3' end of the tags. In view of enriching the samples with the desired fragments, a PCR amplification with 12 cycles using Phusion polymerase (Finnzymes) was performed with primers complementary to the adapter sequences. The resulting fragments of $85 \mathrm{bp}$ were purified by excision from a $6 \%$ polyacrylamide TBE gel. DNA was eluted from the gel debris with NEBuffer 2 by gentle rotation for $2 \mathrm{hrs}$ at room temperature. Gel debris were removed using Spin-X Cellulose was performed by applying $4 \mathrm{pM}$ of each sample to individual lanes of an Illumina $1 \mathrm{G}$ by sorting and counting the unique tags. 
The sequence files of each DGE library were analyzed by Skuldtech company (Montpellier, France). Comparisons of DGE libraries were performed using the exact number of tags in each library, , and assumed that each tag has an equal chance of being detected (Piquemal et al. 2002). The associated statistical values were obtained from Pearson correlations between tag counts and expressed as p-values (Supplementary mathematical appendix). In order to identify potentially differentially expressed genes, the two DGE libraries were scrutinized for tags that showed the most differential counts, using a p-value $<0.001$. Only tags showing a minimum of 10 occurrences in at least one of the two libraries were considered. This resulted in 2214 distinct tags that showed different counts (figure 1). Among them, 711 could be assigned to the EST library. Over these 711 tags, 60 were randomly chosen such that they were over-represented in one of the two salinity conditions, with a 2-fold count difference threshold. Conversely, a p-value $>0.1$ was applied to identify tags that showed conserved counts between the 2 salinities. Under such conditions, a total of 2959 distinct tags were identified (figure 1), among which 785 could be assigned to the EST library. Twelve of them were selected according to their apparent highest stability. The selected tags were locally blasted against the RNA-seq library, and all the sequences corresponding to the selected tags (100\% identity) were aligned with ClustalX v2.1 software using standard settings (Larkin et al. 2007). Primers were designed from each resulting consensus sequence with the online RealTime PCR software tool from Integrated DNA Technologies 210 (http://eu.idtdna.com/scitools/Applications/RealTimePCR/), using the following settings: optimal Tm of $62^{\circ} \mathrm{C}$, optimal length of $22 \mathrm{nt}$ and optimal GC content of $50 \%$. 
Reverse transcription of male RNA extracts was performed with oligodT primers on $250 \mu \mathrm{g}$ RNA, using the transcriptor first strand cDNA synthesis kit (Roche). A template-primer mixture consisting of $250 \mu \mathrm{g}$ RNA and $2.5 \mu \mathrm{M}$ oligodT was denatured at $65^{\circ} \mathrm{C}$ for $10-\mathrm{min}$ and immediately cooled on ice. The reaction (in $20 \mu 1$ final) was supplemented with reaction buffer (1X), dNTPs (1 mM each), RNase inhibitor (20 U) and reverse transcriptase (10 U), incubated for $1 \mathrm{hr}$ at $50^{\circ} \mathrm{C}$, then heated for $5 \mathrm{~min}$ at $85^{\circ} \mathrm{C}$ and immediately cooled on ice. The resulting cDNAs were diluted 10 times with $180 \mu 1 \mathrm{H}_{2} \mathrm{O}$ and stored at $-20^{\circ} \mathrm{C}$ until use.

221 PCR amplifications were carried out in 384-well plates with a LightCycler 480 (Roche) in a final volume of $6 \mu 1$ containing $3 \mu 1$ of SYBR Green I Master mix (Roche), $2 \mu 1$ of cDNA and $0.5 \mu \mathrm{M}$ of each primer. Amplifications were performed in duplicate or in triplicate with an initial denaturation step of 10 min at $95^{\circ} \mathrm{C}$ followed by 40 cycles of denaturation at $95^{\circ} \mathrm{C}$ for $10 \mathrm{~s}$, annealing at $60^{\circ} \mathrm{C}$ for $10 \mathrm{~s}$ and elongation at $72^{\circ} \mathrm{C}$ for $10 \mathrm{~s}$. Amplifications were followed by a melting procedure, consisting of a brief denaturation at $95^{\circ} \mathrm{C}$ for $5 \mathrm{sec}$, a cooling step at $65^{\circ} \mathrm{C}$ for $1 \mathrm{~min}$ and a slow denaturation to $97^{\circ} \mathrm{C}$. Amplification efficiency of each primer pair was calculated from dilution curves generated using serial dilutions $(1: 1,1: 2$, $1: 5,1: 10,1: 20,1: 50,1: 100)$ of a unique cDNA pool, consisting of a mix of 12 cDNAs (4 cDNAs per - 0, 35 and $70 \mathrm{psu}$ ). A linear regression was applied on the resulting dilution curves and the regression coefficient $\left(\mathrm{R}^{2}\right)$ as well as the slope were calculated. Primer pairs were validated only when their corresponding $\mathrm{R}^{2}$ was higher than 0.99. Amplification products were also verified by analyzing the shape of their corresponding melting curve and by measuring their size on agarose gel electrophoresis. Only the primers yielding a single product, without any primer-dimers, were validated. Each qPCR run contained a no-template control for every primer pair. Cycle of quantification $(\mathrm{Cq})$ values were calculated with the LightCycler software, using the second derivative method. Results were expressed as changes 
in relative expression according to the $2^{-\Delta \Delta \mathrm{Cq}}$ method (Pfaffl 2001). Cq values were first corrected with the amplification efficiency of each primer pair according to the following equation: $\mathrm{Cq}_{\mathrm{E}=100 \%}=\mathrm{Cq}_{\mathrm{E}}(\log (1+\mathrm{E}) / \log (2))$, where $\mathrm{E}$ is the efficiency and $\mathrm{Cq}_{\mathrm{E}}$ the uncorrected Cq values. Then the corrected Cqs of each gene of interest were normalized with the mean $\mathrm{Cq}$ of reference genes $(\Delta \mathrm{Cq})$, and $\Delta \mathrm{Cq}$ values were related to the average $\Delta \mathrm{Cq}$ value of all samples. All qPCR results were analyzed with the GenEx Pro package (MultiD Analyses, Sweden).

\section{Results}

\section{Main features of the sequence data}

Considering the scarcity of tilapia sequences in public databases, the first step of this study consisted in establishing a large collection of expressed sequences. It was generated from fish collected in the Sine Saloum estuary. To make this transcript collection as comprehensive as possible, individuals from the three locations (with salinities of 40, 53 and $95 \mathrm{psu}$ ) and at all stages of sexual maturity were represented. RNA-seq generated a total of 28,981,363 bp. Sequence assembly resulted in 30,022 contigs and 86,291 singletons, and contig length ranged from 150 to $>3000 \mathrm{bp}$. Nearly $60 \%$ of them could be annotated from public databases. The main features of sequence data are displayed in Table 1.

As a starting point to investigate differential gene expression in the testis of fish reproducing under different salinities, two DGE libraries were also constructed from 5 males collected at the locations displaying the most extreme salinities: Missirah (salinity $40 \mathrm{psu}$ ) and Kaolak (salinity $95 \mathrm{psu}$ ). Their sequencing resulted in a total of 367,813 and 537,303 tags, respectively, and represented 39,687 and 69,499 unique tags. Among these unique tags, 7,119 and 11,850 could be assigned to the transcript library, respectively. 
All this sequence data was organized into an interactive navigation system. This platform includes a sequence viewer that enables exploration of consensus sequences, gene families, putative associated proteins, SNPs or allelic mutations, as well as a local BLAST alignment tool to search for peptidic and nucleotidic motifs in the database. It also allows comparisons of DGE libraries under various stringency conditions. In addition, it gives access to raw sequence data and allows exportation of sequences in fasta format. This platform has been made publicly available and can be accessed through the following address: http://www.skuldtech.com/tilapia/tilapia_menu.php. Details about the functions of this platform may be provided upon request.

\section{Primer validation}

The 72 novel primer pairs designed in the present study were first verified for their ability to amplify one single product with an acceptable efficiency. Under the conditions tested, 15 primer sets gave rise to either a lack of amplification or secondary products, as revealed by melting curve analysis and agarose gel electrophoresis. Furthermore, 3 additional pairs yielded poor amplification efficiencies, with linear regression coefficients $<0.99$. For these reasons, 18 primer sets were excluded from the analyses. Amplification efficiencies of the 54 remaining primer pairs (43 potential genes of interest and 11 potential reference genes) ranged between 0.8 and 1.1. The sequence of these primers, together with the amplicon length and

281 the amplification efficiency are displayed in Table 2.

282 Because genomic information regarding intron-exon boundaries was not available for Sarotherodon melanotheron, it was not possible to design primers spanning different exonic regions. For this reason, two DNase treatments were applied on each RNA sample: one directly on the columns during the extraction procedure, and a second one in solution, on the 
RNA eluates. Relatively high levels of background genomic DNA were detected in single DNAse treated RNA extracts (Cq ranged from 23.9 to 31.5$)$. This signal was not detected in twice DNAse treated samples $(\mathrm{Cq}>35)$, indicating the necessity of 2 DNAse treatments for elimination of genomic DNA in cDNA samples.

The optimal primer concentration was also assessed. For each primer pair, 4 concentrations $(0.25,0.5,0.75$ and $1 \mu \mathrm{M})$ were tested. Comparison of amplification plots showed that $\mathrm{Cq}$ values were steady for the 3 highest concentrations, whereas they were in most cases higher for $250 \mathrm{nM}$. Besides, melting profiles indicated the absence of primer-dimer or secondary peak for all tested concentrations. For these reasons, primers were used at a final concentration of $500 \mathrm{nM}$ in all subsequent experiments.

\section{Estimation of experimental reproducibility}

As for any new assay, evaluation of the experimental biases that may impair quantitative results is also essential. To address this critical issue, experimental reproducibility was first assessed through the following nested protocol: RNA was extracted in duplicate, and reversetranscription and qPCR were both performed in triplicate, which resulted in $18 \mathrm{Cq}$ measurements per sample and per gene. This protocol was applied with 2 different genes (transcript_AVA2_10563 and transcript_AVA3_453) that produced nearly similar mean Cq values $(\sim 20)$, on 3 individual fish samples originating from 3 distinct salinities, and repeated two times independently. Results revealed that the highest source of variation (expressed as SD of Cqs), after that originating from samples, could be attributed to the reverse transcription reaction (SD ranged from 0.095 to 0.409 ); conversely, RNA extraction produced the lowest variation (SD ranged from 0 to 0.166 ), while SD of qPCR repeats varied from 0.076 to 0.130 . When the same experiment was repeated using $1 \mu 1$ of template cDNA instead 
of $2 \mu 1$, the SD of qPCR replicates dramatically increased as it varied from 0.283 to 0.369 . For

311

312

313 this reason, the amount of cDNA used was always $2 \mu 1$, as stated in the MM section.

Since reverse transcription was the main source of variability, we also evaluated its reproducibility across a range of RNA concentrations. For this purpose, serial dilutions $(1: 1$, $1: 2,1: 5,1: 10,1: 20,1: 50,1: 100)$ were prepared from a pool of RNAs $(50 \mathrm{ng} / \mu \mathrm{l})$ and each dilution $(50 \mathrm{ng} / \mu \mathrm{l}$ to $0.5 \mathrm{ng} / \mu \mathrm{l})$ was reverse transcribed. The corresponding cDNAs were amplified with 2 primer pairs (transcript_AVA2_10563 and transcript_AVA3_453) and Cq values were plotted against the logarithm of the initial RNA concentration. This experiment was repeated twice independently. In each case, it revealed a good linearity with a $\mathrm{R}^{2} \geq 0.99$ and amplification efficiencies were comprised between 0.63 and 0.86 . Results obtained with the primer pair transcript_AVA3_453 are displayed in Figure 2.

Taken altogether, these results suggest that our experimental workflow is trustworthy and should not supply substantial experimental variability to the biological results.

\section{Validation of reference genes}

Another crucial point consisted in validating suitable genes that could be used as appropriate reference genes for subsequent relative quantifications. The twelve genes previously identified as potential references were assayed with geNorm (Vandesompele et al. 2002) and NormFinder (Andersen et al. 2004) algorithms. For this end, their Cq values were measured in a set of 12 fish samples collected from 3 salinities (0, 35 and 70 psu, 4 fish / salinity), and their stability examined. Only the genes displaying an M-value $<0.55$ (with geNorm software) and an SD $<0.5$ (with NormFinder software) were conserved, which resulted in the selection of 5 of them. Then, these 5 genes were amplified in a set of 22 fish originating from the 3 salinity locations. Analysis of their expression stability across samples with geNorm and 
NormFinder (both ignoring and taking salinity groups into account) revealed very congruent results. It led to the validation of 4 of these genes showing an M-value $<0.42$ and an SD $<$ 0.36 (Table 3). According to NormFinder, using these 4 genes as reference instead of only one would decrease the accumulated SD by nearly 2 (Table 3 ).

\section{Discussion}

The present study is the first large-scale analysis of the transcriptome of the black-chinned tilapia, an ecologically fascinating fish species with exceptional adaptive capacities, especially in regards to its reproductive behavior. Since Sarotherodon melanotheron is a nonmodel species, the procedure was divided in two separate stages, in order to provide a resource that will be valuable in any study dealing with the reproduction of this fish. The first one consisted of building a large transcript collection from two major organs involved in reproduction, that is liver and gonads (Mommsen\& walsh 1988; Wiegand 1996), collected from fish at all stages of sexual maturity and under different salinities. The purpose of this collection was neither to evaluate the total number of transcripts expressed in these organs nor to estimate a transcriptome coverage, as is now the case for most RNA-seq projects in model animals (Wang et al. 2009), but rather to provide a first genomic resource in this species for which only a very limited number of sequences were available so far (Tine et al. 2008). It is worth mentioning that when these newly obtained sequences were annotated, the genome sequence of the Nile tilapia, Oreochromis niloticus, had not yet been released, which is the reason why almost none of these annotations that can be found on the tilapia database website (http://www.skuldtech.com/tilapia/tilapia_menu.php) refer to O. niloticus. However, a new annotation round performed on a selected set of sequences revealed no major changes in the protein prediction (data not shown), probably because the genome annotation of $O$. niloticus 
was performed automatically. Moreover, the 'export' function of the sequence viewer enables easy updates of alignments and annotations.

In contrast, the second stage of this project aimed at addressing a more specific question on the reproductive biology of $S$. melanotheron, i.e. the identification of genes in male gonads subjected to changes in their expression according to salinity. As demonstrated by several groups, DGE is particularly suited for quantification of transcript abundance (Asmann et al. 2009), especially in non-model organisms for which no reference genome is available (Hong et al. 2011). For this reason, DGE libraries were compared between fish living in the most extreme salinity environments of the Sine saloum estuary. The library comparison enabled identification of hundreds of genes potentially differentially expressed between the two environments. This list of genes is likely to serve as a wealthy basis for the deeper understanding of the molecular mechanisms that allow $S$. melanotheron heudelotii to reproduce in such a wide range of salinities. Furthermore, a set of 43 genes of interest has been validated in the present work. Even though analysis of their putative role in the adaptation of male spermatogenesis to salinity is beyond the scope of this article and will be the focus of a complementary study, a first look at their predicted function indicates that several of them have already been described as playing a key role in spermatogenesis or in homeostasis. For instance, contig_Tilapia_90_27008 matches a MORC family CW-type zinc finger 2 protein, which absence was shown to trigger the stop of spermatogenesis in mice (Perry\& Zhao 2003); contig_Tilapia_90_21432 corresponds to a seminal plasma glycoprotein, which harbors the faculty to immobilize sperm cells in mice as well (Mochida et al. 2002); contig_Tilapia_90_947 corresponds to a Na+/K+-transporting ATPase subunit alpha-1, which is involved in the active ion excretion and uptake for maintaining the 
intracellular ionic balance (Lorin-Nebel et al. 2012). Finally, of these 43 genes, six did not match any known protein.

Although often overlooked, validation of candidate genes identified from NGS data by labbench-scale routine methods, such as real-time PCR, requires a number of prior evaluations. This is especially true for the accurate selection of reference genes in relative expression, as it was extensively demonstrated that stability of housekeeping genes greatly depend on the species, tissue, developmental stage, and experimental conditions (McCurley\& Callard 2008; Tang et al. 2012). Here, the use of geNorm and NormFinder algorithms led to very congruent results, and identified 4 genes as the most stably expressed accross fish individuals and environmental salinities. It also indicated that using 4 genes simultaneously would result in lower standard deviations. Those 4 genes, which could be attributed a putative function with good confidence, all belong to the list of potential housekeeping genes described in humans (Eisenberg\& Levanon 2003).

It is acknowledged that the reverse transcription step accounts for a large part of variability in a qPCR assay (Bishop et al. 1997). In order to limit this bias, all the primers were selected in the most $3^{\prime}$ region of the transcripts; this was made easy by the $3^{\prime}$ tag approach that was used for DGE. Then, combined with the use of oligo-dTs, this dramatically reduced the probability to obtain cDNAs that could not be amplified by the designed primers because of incomplete reverse transcription. Although reverse transcription was the main source of variability in the present case, it was yet very limited, as illustrated by the RNA dilution curve that showed a good linearity. Likewise, cDNA dilution curves showed excellent linearity over two logs for the 54 primer pairs. The $\mathrm{Cq}$ values measured with all the primer pairs on 22 individual cDNAs from fish collected at different salinities were all comprised within this range (not shown). This indicates that the range of dilutions used to measure the amplification 
efficiencies was sufficient to cover most, if not all, RNA concentrations of the targeted genes that can be found in individual samples. This was expected since the sample used for dilutions consisted of a mix of 12 different cDNAs, and as such was supposed to comprise most expressed RNAs at highly variable concentrations.

In conclusion, the present study has generated a large transcriptomic resource that will be valuable for a great number of studies focusing on the functional genomics of this interesting fish, and more broadly of any species presenting salinity-related plasticity. It also identified and validated a large set of genes that will provide a significant tool for the deeper understanding of the molecular mechanisms that allow S. melanotheron heudelotii to reproduce in a wide range of salinities. Finally, this resource will also provide useful tools for population genetics studies on S. melanotheron (Consortium et al. 2013), but also on many other phylogenetically-related species.

\section{Acknowledgements}

This study was supported by an INSU-EC2CO grant (IPREP, 2010-2012). We are thankful to Dr. Bruno Guinand for critical reading of this manuscript. We are also grateful to Laurent Manchon and Fabien Pierrat for their input regarding mathematical treatment of the sequence data.

\section{References}

Andersen CL, Jensen JL, Ørntoft TF (2004) Normalization of Real-Time Quantitative Reverse Transcription-PCR Data: A Model-Based Variance Estimation Approach to 
Identify Genes Suited for Normalization, Applied to Bladder and Colon Cancer Data Sets. Cancer Research 64, 5245-5250.

Asmann YW, Klee EW, Thompson EA, et al. (2009) 3 ' tag digital gene expression profiling of human brain and universal reference RNA using Illumina Genome Analyzer. BMC Genomics 10, 11.

Bishop GA, Rokahr KL, Lowes M, et al. (1997) Quantitative reverse transcriptase-PCR amplification of cytokine mRNA in liver biopsy specimens using a non-competitive method. Immunology and Cell Biology 75, 142-147.

Bustin SA, Beaulieu JF, Huggett J, et al. (2010) MIQE precis: Practical implementation of minimum standard guidelines for fluorescence-based quantitative real-time PCR experiments. Bmc Molecular Biology 11, 5.

Bustin SA, Benes V, Garson JA, et al. (2009) The MIQE Guidelines: Minimum Information for Publication of Quantitative Real-Time PCR Experiments. Clinical Chemistry 55, 611-622.

Consortium MERPD, Arranz SE, Avarre JC, et al. (2013) Permanent Genetic Resources added to Molecular Ecology Resources Database 1 December 201231 January 2013. Molecular Ecology Resources 13, 546-549.

Duponchelle F, Cecchi P, Corbin D, Nunez J, Legendre M (2000) Variations in fecundity and egg size of female Nile tilapia, Oreochromis niloticus, from man-made lakes of Cote d'Ivoire. Environmental Biology of Fishes 57, 155-170.

Duponchelle F, Panfili J (1998) Variations in age and size at maturity of female Nile tilapia, Oreochromis niloticus, populations from man-made lakes of Cote d'Ivoire. Environmental Biology of Fishes 52, 453-465. 
Eisenberg E, Levanon EY (2003) Human housekeeping genes are compact. Trends in Genetics 19, 362-365.

Fraser BA, Weadick CJ, Janowitz I, Rodd FH, Hughes KA (2011) Sequencing and characterization of the guppy (Poecilia reticulata) transcriptome. BMC Genomics 12, 14.

Hong LZ, Li J, Schmidt-Kuntzel A, Warren WC, Barsh GS (2011) Digital gene expression for non-model organisms. Genome Research 21, 1905-1915.

Larkin MA, Blackshields G, Brown NP, et al. (2007) Clustal W and clustal X version 2.0. Bioinformatics 23, 2947-2948.

Legendre M, Cosson J, Hadi Alavi SM, Linhart O (2008) Activation of sperm motility in the euryhaline tilapia Sarotherodon melanotheron heudelotii (Dumeril, 1859) acclimatized to fresh, sea and hypersaline waters. Cybium, 181-182.

Legendre M, Ecoutin JM (1989) Suitability of brackish water tilapia species from the Ivory Coast for lagoon aquaculture. I - Reproduction. . Aquatic Living Resources 2, 71-79.

Lorin-Nebel C, Avarre JC, Faivre N, et al. (2012) Osmoregulatory strategies in natural populations of the black-chinned tilapia Sarotherodon melanotheron exposed to extreme salinities in West African estuaries. Journal of Comparative Physiology BBiochemical Systemic and Environmental Physiology 182, 771-780.

McCurley A, Callard G (2008) Characterization of housekeeping genes in zebrafish: malefemale differences and effects of tissue type, developmental stage and chemical treatment. Bmc Molecular Biology 9, 102.

Mochida K, Matsubara T, Andoh T, et al. (2002) A novel seminal plasma glycoprotein of a teleost, the Nile tilapia (Oreochromis niloticus), contains a partial von Willebrand 
factor type D domain and a zona pellucida-like domain. Molecular Reproduction and Development 62, 57-68.

Mommsen TP, walsh PJ (1988) Vitellogenesis and oocyte assembly. In: Fish Physiology, Vol XI, The Physiology of Developing Fish, Part A. Eggs and Larvae (eds. Hoar WS, Randall DJ), pp. 347-406. Academic press, San Diego.

Ogari J, Dadzie S (1988) The food of the Nile perch, Lates niloticus (L.), after the disappearance of the haplochromine cichlids in the Nyanza Gulf of lake Victoria (Kenya). Journal of Fish Biology 32, 571-577.

Panfili J, Mbow A, Durand JD, et al. (2004) Influence of salinity on the life-history traits of the West African black-chinned tilapia (Sarotherodon melanotheron): Comparison between the Gambia and Saloum estuaries. Aquatic Living Resources 17, 65-74.

Panfili J, Thior D, Ecoutin JM, Ndiaye P, Albaret JJ (2006) Influence of salinity on the size at maturity for fish species reproducing in contrasting West African estuaries. Journal of Fish Biology 69, 95-113.

Perry J, Zhao Y (2003) The CW domain, a structural module shared amongst vertebrates, vertebrate-infecting parasites and higher plants. Trends in Biochemical Sciences 28, $576-580$.

Pfaffl MW (2001) A new mathematical model for relative quantification in real-time RTPCR. Nucleic Acids Research 29, 6.

Piquemal D, Commes T, Manchon L, et al. (2002) Transcriptome analysis of monocytic leukemia cell differentiation. Genomics 80, 361-371.

Stearns SC, Crandall RE (1984) Plasticity for age and size at sexual maturity: a life-history response to unavoidable stress. In: Fish reproduction: strategies and tactics., pp. 1333. 
Stewart KM (1988) Changes in condition and maturation of the Oreochromis niloticus L. population at Freguson's Gulf, Lake Turkana, Kenya. Journal of Fish Biology 33, 181-188.

t Hoen PAC, Ariyurek Y, Thygesen HH, et al. (2008) Deep sequencing-based expression analysis shows major advances in robustness, resolution and inter-lab portability over five microarray platforms. Nucleic Acids Research 36, 11.

Tang Y-k, Yu J-h, Xu P, et al. (2012) Identification of housekeeping genes suitable for gene expression analysis in Jian carp (Cyprinus carpio var. jian). Fish \& Shellfish Immunology 33, 775-779.

Tine M, de Lorgeril J, D'Cotta H, et al. (2008) Transcriptional responses of the black-chinned tilapia Sarotherodon melanotheron to salinity extremes. Marine Genomics 1, 37-46.

Tine M, Guinand B, Durand JD (2012) Variation in gene expression along a salinity gradient in wild populations of the euryhaline black-chinned tilapia Sarotherodon melanotheron. Journal of Fish Biology 80, 785-801.

Vandesompele J, De Preter K, Pattyn F, et al. (2002) Accurate normalization of real-time quantitative RT-PCR data by geometric averaging of multiple internal control genes. Genome Biology 3, research0034.0031 - research0034.0011.

Wang Z, Gerstein M, Snyder M (2009) RNA-Seq: a revolutionary tool for transcriptomics. Nature Reviews Genetics 10, 57-63.

Wiegand MD (1996) Composition, accumulation and utilization of yolk lipids in teleost fish. Reviews in Fish Biology and Fisheries 6, 259-286. 
522 Figure 1: Comparison of the tag counts in the 2 DGE libraries constructed from fish at two 523 salinity extremes (40 and 95 psu). Comparison was obtained from Pearson correlations 524 between actual tag counts and results expressed as p-values. A low p-value indicates a high 525 level of biological significance. For easier visualization, values were normalized to the 526 number of total tags of each library (count/total number of reads $* 10000$ ), and each tag was 527 color-coded according to its representation in each library (reflected by its p-value).

529 Figure 2: Reproducibility of the reverse transcription step. Serial dilutions were prepared from 530 a pool of RNAs and each dilution $(50 \mathrm{ng} / \mu 1$ to $0.5 \mathrm{ng} / \mu \mathrm{l})$ was reverse transcribed. The 531 corresponding cDNAs were amplified with the primer pair transcript_AVA3_453 (A) and Cq

532 values were plotted against the logarithm of the initial RNA concentration (B). 
535 RNA-seq and DGE libraries have been organized into an interactive database that is freely 536 accessible (http://www.skuldtech.com/tilapia/tilapia_menu.php). Moreover, the whole project, 537 including raw DNA sequences, can be found under the SRA study accession SRP022935.

538

539 Author contributions

540 JCA and JDD designed the project. RD, PA, AD, CJ and NF contributed to the experiments.

$541 \mathrm{RD}$ and CC were in charge of fish care. JCA, PA, AD and CJ analyzed the data. JCA and 542 JDD wrote the paper.

543 
544 Table 1 Summary statistics of the RNA-seq data

Statistics for contigs

Number of bases in all contigs

11368093

Number of contigs

30022

Number of contigs in N50

8880

Minimum contig length

150

Maximum contig length

3099

Median contig length

423

GC content of contigs

$53.13 \%$

Statistics for singletons

Number of bases in all singletons

17613270

Number of singletons

86291

Number of singletons in N50

31086

Median singleton length

202

GC content of singletons

$52.63 \%$

545

546

547 
548 Table 2 List of the genes validated by qPCR

\begin{tabular}{|c|c|c|c|}
\hline Sequence name ${ }^{\mathrm{a}}$ & Primer sequence & $\begin{array}{l}\text { Amplicon } \\
\text { length }\end{array}$ & $\begin{array}{l}\text { Amplification } \\
\text { efficiency }\end{array}$ \\
\hline Potential candidate genes & & & \\
\hline Transcript_AVA2_6155 & $\begin{array}{l}\text { TGTCAGAGGGTAAAGCAAAGGG } \\
\text { GTAACTTTCCCACACGCCCA }\end{array}$ & 127 & 0,97 \\
\hline Transcript_AVA1_52992 & $\begin{array}{l}\text { GCCACACAGAACAATGGGAATG } \\
\text { ATCATGTTCGACGTCACTTCTCG }\end{array}$ & 102 & 0,98 \\
\hline Transcript_AVA1_55478 & $\begin{array}{l}\text { CTAACAGAGGATGAGACGGGTG } \\
\text { TGACTTGTGGCTGCAGACTAC }\end{array}$ & 142 & 1,00 \\
\hline Transcript_AVA2_10563 & $\begin{array}{l}\text { ATTGCTCCTTGACGTACCCAC } \\
\text { GAAAGACGTCCACCTGGCC }\end{array}$ & 113 & 1,01 \\
\hline Transcript_AVA2_4300 & $\begin{array}{l}\text { GCTGGAATTGCACTCAACGAC } \\
\text { TGTGACATCCAGGTGAAGGAATG }\end{array}$ & 149 & 1,01 \\
\hline Transcript_AVA3_47460 & $\begin{array}{l}\text { ACGTTGGAGTTGAGTGTCATGG } \\
\text { CTGAGAGGATGTGTTATCTGGCG }\end{array}$ & 115 & 0,97 \\
\hline Contig_Tilapia_90_6346 & $\begin{array}{l}\text { АATTCTCCCTCATTGTCGCCG } \\
\text { CAGGTCTTGAGGCATTTTGTTCC }\end{array}$ & 128 & 0,98 \\
\hline Transcript_AVA1_4937 & $\begin{array}{l}\text { AGAGCCCTGGAACAAACTTGG } \\
\text { CTGCCGATCTTTGTGCTTGTG }\end{array}$ & 128 & 1,04 \\
\hline Contig_Tilapia_90_14414 & $\begin{array}{l}\text { GAACCAGCGTGAACTTTGCAG } \\
\text { ACCGGACCTTATCATTCTTGGC }\end{array}$ & 114 & 0,92 \\
\hline Transcript_AVA1_64597 & $\begin{array}{l}\text { GCTGTTCAAAATCCCACAAGG } \\
\text { TCTCCAAGATGTTATCCATAGTGTG }\end{array}$ & 105 & 0,96 \\
\hline Contig_Tilapia_90_23367 & $\begin{array}{l}\text { тССТССтCAтССтССССтTC } \\
\text { АСАTTCATAGGCACTCCGGTG }\end{array}$ & 111 & 0,97 \\
\hline
\end{tabular}




\begin{tabular}{|c|c|c|c|}
\hline Contig_Tilapia_90_42 & $\begin{array}{l}\text { TGGACAGGAAGCAATGAGGAAG } \\
\text { TCCAGCCTAAAGACTTTCCTGC }\end{array}$ & 135 & 1,04 \\
\hline Transcript_AVA1_66083 & $\begin{array}{l}\text { CAAAGGAGCTTGATGCTATTGTA } \\
\text { ACCCTGCAAATGTTCTCTTTC }\end{array}$ & 116 & 1,10 \\
\hline Contig_Tilapia_90_10837 & $\begin{array}{l}\text { TGACCAGGCTCAGTTCAAAGATG } \\
\text { СTGTCTGCAACTCTGGGTAAGG }\end{array}$ & 109 & 1,01 \\
\hline Transcript_AVA3_28576 & $\begin{array}{l}\text { CATCCCACTTTGGCAGAAAACAG } \\
\text { GCTGCTGTCATTTATTCAACACC }\end{array}$ & 152 & 0,99 \\
\hline Contig_Tilapia_90_27008 & $\begin{array}{l}\text { GAGAACACAGGCACGGAAGAG } \\
\text { TGGATGACAGGCTCAGTTCAATG }\end{array}$ & 110 & 1,00 \\
\hline Contig_Tilapia_90_26617 & $\begin{array}{l}\text { TCCTCGGCTACATGCAATTACG } \\
\text { GGCCGAACAGGCTCTTTTATG }\end{array}$ & 109 & 0,86 \\
\hline Transcript_AVA3_18623 & $\begin{array}{l}\text { CACATGCAAGAGAAACAAGGAGC } \\
\text { TGCCACСTTTTCCCАTCСТTG }\end{array}$ & 107 & 0,92 \\
\hline Contig_Tilapia_90_2777 & $\begin{array}{l}\text { ACCATCACCAACGATAAGGGC } \\
\text { CGGCGATTTTGTCCCTCTGAAG }\end{array}$ & 109 & 0,88 \\
\hline Contig_Tilapia_90_2321 & $\begin{array}{l}\text { CTGGAGCTGTAAGTGGGTGAC } \\
\text { GCTTGTTAAAACCTGGGCGTC }\end{array}$ & 129 & 0,99 \\
\hline Contig_Tilapia_90_10643 & $\begin{array}{l}\text { GAGTGGGCTAACAATGTCAAACG } \\
\text { TTATTCCCAGTTCCTGCAGAGTG }\end{array}$ & 106 & 0,85 \\
\hline Transcript_AVA1_24409 & $\begin{array}{l}\text { TCTTTGGAGGGAACATGGTGTAC } \\
\text { GTGCTGTGACTCTGTCGGAAG }\end{array}$ & 102 & 0,90 \\
\hline Contig_Tilapia_90_8343 & $\begin{array}{l}\text { AGAATCAGTGCCGTCCTGTTC } \\
\text { CGATGAGGCACACCAGTATATCC }\end{array}$ & 125 & 0,82 \\
\hline Contig_Tilapia_90_2464 & $\begin{array}{l}\text { GACCTTCCTCTGAGTGTGATGC } \\
\text { CCAAAATCTGAAGCTGTGCGTG }\end{array}$ & 128 & 0,86 \\
\hline Transcript_AVA1_35277 & CGTGGCTATGGACAATTTTGGG & 107 & 0,87 \\
\hline
\end{tabular}


CCTCGGCAAAAGTCAGCAAAAG

Contig_Tilapia_90_2942

Transcript_AVA3_14200

Transcript_AVA3_33497

Transcript_AVA2_28399

Contig_Tilapia_90_21432

Contig_Tilapia_90_6938

Contig_Tilapia_90_2253

Contig_Tilapia_90_2414

Contig_Tilapia_90_1393

Transcript_AVA1_9958

Contig_Tilapia_90_2469

Transcript_AVA1_58357
CTCTGCCCTTCTATCTGTGTTCG

111

1,02

TCAGTCCGTTCAGTCCTCTCC

TGGAGCAAACAGGAAGAGAAGG

114

0,91

CCCTGTCTTCGGAAACCAATTG

CTACATGCTCGGAGGGAAGATTG

115

1,01

AGATATGGTAGAGTAGTAGGACGCC

ACGGTGTACTTGGACATTCAGG

136

1,00

AAAGCAAAGGGAAGACCGGAG

ACAGAACTCGTGATCGCTGC

102

0,84

TGCAGTCTACACAACCACACTC

TGCTCTGAACAGTTTGGGCTC

116

0,88

ATGAGAAGCTGGTAACCGTGTG

ACCCACACCAAACTGACCAATC

117

0,89

ACCAAAGCCGACCTCATTAACA

AGTCGGGATGGCTGGATTTG

142

0,91

ACCAACAGTCATTGCTCCCAC

CTTTCACACCCTCTTCCCTCG

149

0,84

CACCAACATTGAGCTGGCAAC

CTCCTTCTCACCCGGCAG

104

0,86

TGGCCTCACATTCAGCCTTG

CGAGAACGTCAGAGAAGGTGC

150

0,86

GAAATTTGGCAGCTCGTGGC

ATTCCGACGCCTTCTCAACC

122

0,86

CATGCCGACCCAAACATAAATCG

AGACAAGAGTGCCAACATCCAG

116

0,86 


\begin{tabular}{|c|c|c|c|}
\hline Transcript_AVA3_142 & $\begin{array}{l}\text { ATTGAGAACCCCAACAGAGTGG } \\
\text { TCCTTTGCCTTCTGCTTCTCG }\end{array}$ & 119 & 0,87 \\
\hline Contig_Tilapia_90_8891 & $\begin{array}{l}\text { CTGGTATTGTTAAAAGGCTGGCC } \\
\text { TCATTCTGGACTCCTGCAACAC }\end{array}$ & 150 & 0,90 \\
\hline Contig_Tilapia_90_947 & $\begin{array}{l}\text { GTATGTCTCTTTCTCCACCCAACC } \\
\text { ACGTTGCCCTCAGAATGTACC }\end{array}$ & 143 & 0,85 \\
\hline Contig_Tilapia_90_9321 & $\begin{array}{l}\text { ACAGTTCATCGGACAGGTTCAG } \\
\text { AGCGACAGAGTGAAATCATGGAC }\end{array}$ & 150 & 0,95 \\
\hline Contig_Tilapia_90_26561 & $\begin{array}{l}\text { TCCGCACCCTTAAACTCACAAC } \\
\text { GGAATGGCACCATGTTTACAGC }\end{array}$ & 147 & 0,88 \\
\hline Potential reference genes & & & \\
\hline Transcript_AVA2_1624 & $\begin{array}{l}\text { AAGGACTGGCTTATGCTGATAA } \\
\text { GTGATTCAGGTAAGTGACAATGC }\end{array}$ & 86 & 1,01 \\
\hline Contig_Tilapia_90_13722 & $\begin{array}{l}\text { GCAATTCGGCTTTCCATGACAG } \\
\text { AGCAGAGATAGACATGATTTGGGAG }\end{array}$ & 135 & 0,96 \\
\hline Transcript_AVA3_453 & $\begin{array}{l}\text { TGCACACTCTCAAAGATCCCG } \\
\text { AGTGACAGAGCCCAAGAAACG }\end{array}$ & 105 & 1,01 \\
\hline Contig_Tilapia_90_1351 & $\begin{array}{l}\text { TCGGATAACATCGCCACACTG } \\
\text { GAGCCATCTGTCATCTAAACCCTC }\end{array}$ & 148 & 1,00 \\
\hline Transcript_AVA2_10375 & $\begin{array}{l}\text { AAATTCATTGGTTTGGAGCGGC } \\
\text { GCCTGCTAGTGGGATACCATTC }\end{array}$ & 110 & 1,04 \\
\hline Contig_Tilapia_90_29868 & $\begin{array}{l}\text { GTGCCCGAAACAATCCAGAAAC } \\
\text { TCTGAACTCGAACTGCCGAAC }\end{array}$ & 149 & 0,93 \\
\hline Contig_Tilapia_90_1736 & $\begin{array}{l}\text { CTGCGGTCTAAGATGAGCCAAG } \\
\text { AACGGTGGATGCTGGATACTTG }\end{array}$ & 126 & 1,07 \\
\hline Contig_Tilapia_90_21150 & $\begin{array}{l}\text { AGGCCACTCAAACATCACCC } \\
\text { GTTTGCCCTGGCTTTGATGTG }\end{array}$ & 110 & 0,97 \\
\hline
\end{tabular}




$\begin{array}{llcc}\text { Transcript_AVA3_16746 } & \text { GATGTTCTTATTGCAGACGGTGG } & 118 & 0,97 \\ & \text { ACTGCGGACTCTGTGTAATtGC } & & \\ \text { Contig_Tilapia_90_7452 } & \text { TTTTGATCGTAGTCGTGGGCTC } & 102 & 0,87 \\ & \text { CATGAGGATGCTTGTGGAAGATAAAC } & & \\ \text { Contig_Tilapia_90_3058 } & \text { CATGTTGCTTTCTGCCTCAGTG } & 108 & 0,91 \\ & \text { CGCATCTCCGAGCAGTTCAC } & & \end{array}$

\footnotetext{
${ }^{a}$ Names of the sequences as they appear on the web sequence viewer

(http://www.skuldtech.com/tilapia/tilapia_menu.php)
} 
Table 3 Expression stability of the 4 selected reference genes

\begin{tabular}{llll}
\hline & geNorm & \multicolumn{2}{l}{ NormFinder } \\
\hline Sequence name & M-value & SD & Acc. SD \\
\hline Contig_Tilapia_90_7452 & 0,337 & 0,297 & 0,297 \\
Contig_Tilapia_90_13722 & 0,395 & 0,319 & 0,218 \\
Transcript_AVA3_453 & 0,412 & 0,352 & 0,187 \\
Contig_Tilapia_90_3058 & 0,337 & 0,355 & 0,166
\end{tabular}

A low M-value or standard deviation indicates high expression stability. The combined use of the 4 genes as reference decreases the accumulated standard deviation. 


\section{Figure 1}

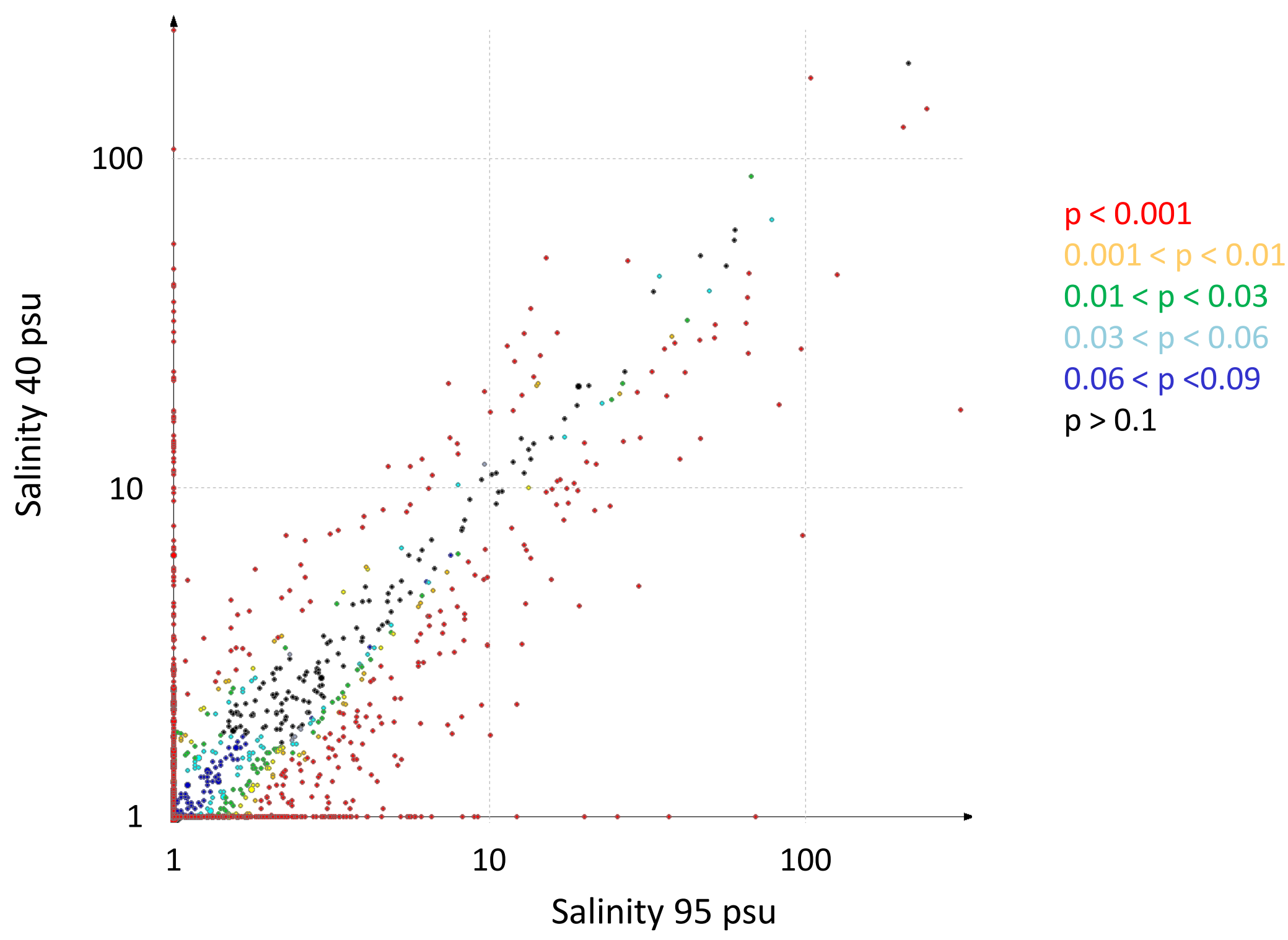




\section{Figure 2}

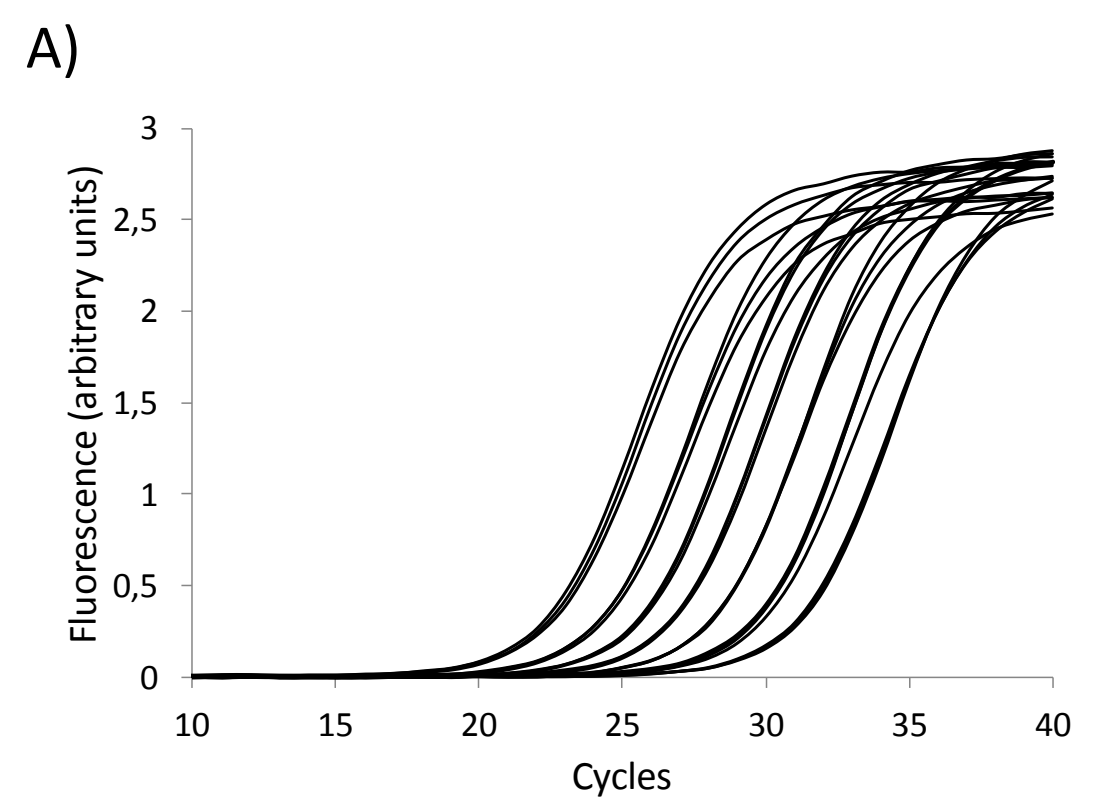

B)

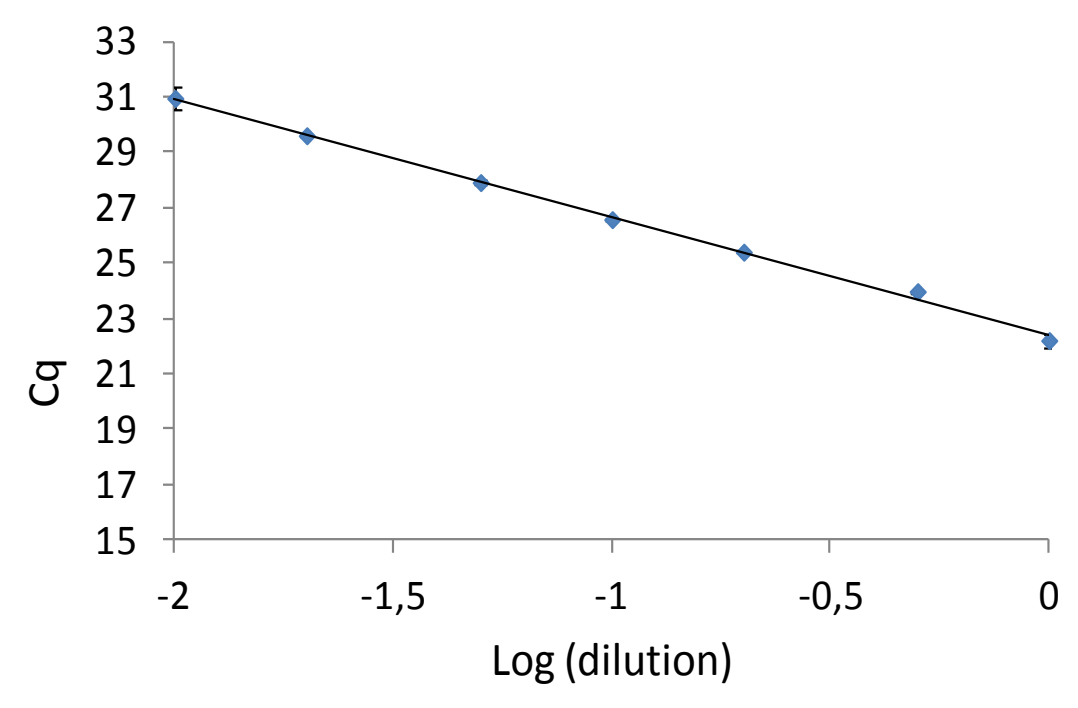




\section{Mathematical approach: analysis of differential expression}

When comparing two populations of tags, the problem is to distinguish random fluctuation from a biologically significant change. One must calculate the probability for a given tag to be observed $x$ times in a sample of $N_{1}$ elements and $y$ times in a sample of $N_{2}$.Using actual experimental series of tag counts, we checked (data not illustrated) that registered variations were in fair agreement with the assumption that $x$ values are binomially distributed:

$$
P_{1}\left(x ; N_{1}\right)=C_{N_{1}}^{x} p^{x}(1-p)^{N_{1}-x}
$$

with: $C_{N}^{x}=\frac{N !}{x !(N-x) !}, \boldsymbol{p}$ being the mathematical individual probability.

When performing an other round of analysis and picking up $y$ tags among $\mathrm{N}_{2}$, the probability is:

$$
P_{2}\left(y ; N_{2}\right)=C_{N_{2}}^{y} p^{y}(1-p)^{N_{2}-y}
$$

and, when picking up $x+y$ times the same tag in $N_{1}+N_{2}$, the probability is :

$$
P_{1,2}\left(x+y ; N_{1}+N_{2}\right)=C_{N_{1}+N_{2}}^{x+y} p^{x+y}(1-p)^{N_{1}+N_{2}-(x+y)}
$$

Let us consider now the conditional probability $P\left(x, y ; N_{1}, N_{2} \mid x+y ; N_{1}+N_{2}\right)$ that, knowing the overall result of two random samplings of $x+y$ tags among $N_{1}+N_{2}$, then $x$ copies of a tag had actually been picked among $N_{1}$ and $y$ among $N_{2}$. According to Bayes' theorem, for two events $A$ and $B$, the probability for $A$ occuring knowing $B$ is :

$$
P(A \mid B)=\frac{P(B \mid A) P(A)}{P(B)}
$$

Using (4) in the present case, we obtain:

$$
P\left(x, y ; N_{1}, N_{2} \mid x+y ; N_{1}+N_{2}\right)=\frac{P\left(x+y ; N_{1}+N_{2} \mid x, y ; N_{1}, N_{2}\right) P\left(x, y ; N_{1}, N_{2}\right)}{P\left(x+y ; N_{1}+N_{2}\right)}
$$

Since the fact that $x$ copies of a tag have been found in $N_{1}$, and $y$ in $N_{2}$ implies that $x+y$ tags occured in $N_{1}+N_{2}$, it follows that: $P\left(x+y ; N_{1}+N_{2} \mid x, y ; N_{1}, N_{2}\right)=1$. Now, considering the two independent binomial distributions (1) et (2), we can write $P\left(x, y ; N_{1}, N_{2}\right)=P_{1}\left(x ; N_{1}\right) P_{2}\left(y ; N_{2}\right)$.

Equation (5) then becomes :

$$
P\left(x, y ; N_{1}, N_{2} \mid x+y ; N_{1}+N_{2}\right)=\frac{P_{1}\left(x ; N_{1}\right) P_{2}\left(y ; N_{2}\right)}{P_{1,2}\left(x+y ; N_{1}+N_{2}\right)}
$$

Combining (1), (2) et (3) in (6), we obtain:

$$
P(x, y \mid x+y)=\frac{C_{N_{1}}^{x} C_{N_{2}}^{y}}{C_{N_{1}+N_{2}}^{x+y}}
$$

The symetry of equation (7) allows to compare independent experiments, with tag libraries of different sizes. A low $\mathrm{P}$ value will allow to consider the variation as being biologically relevant. 